\title{
The Upregulated Expression of Sonic Hedgehog in Motor Neurons after Rat Facial Nerve Axotomy
}

\author{
Chihiro Akazawa, ${ }^{1}$ Hayami Tsuzuki, ${ }^{1}$ Yasuko Nakamura, ${ }^{1}$ Yo Sasaki, ${ }^{1}$ Kanae Ohsaki, ${ }^{2}$ Shun Nakamura, ${ }^{2}$ \\ Yoshihiro Arakawa, ${ }^{3}$ and Shinichi Kohsaka ${ }^{1}$ \\ Departments of ${ }^{1}$ Neurochemistry and ${ }^{2}$ Biochemistry and Cellular Biology, National Institute of Neuroscience, National Center of Neurology and Psychiatry, \\ Kodaira, Tokyo 187-8502, Japan, and ${ }^{3}$ Department of Clinical Research Center, Branch Hospital, Faculty of Medicine, University of Tokyo, Bunkyo-ku, \\ Tokyo 113-8655, Japan
}

Nerve injury leads to the induction of a large number of genes to repair the damage and to restore synaptic transmission. We have attempted to identify molecules whose mRNA expression is altered in response to facial nerve axotomy. Here we report that facial nerve axotomy upregulates Sonic hedgehog (Shh) and its receptor Smoothened (Smo) in facial motor neurons of adult rats, whereas facial nerve axotomy does not upregulate mRNA of Shh or Smo in neonatal rats. We tested whether overexpression of Shh in facial motor neurons of axotomized neonatal rats may promote neuronal survival. Adenovirus-mediated overexpression of Shh, but not that of $\beta$-galactosidase, transiently rescues axotomy-induced neuronal cell death for 3-5 d after axotomy. Finally, the pharmacological inhibitor of Shh signaling, cyclopamine, induces motor neuron death in adult rats after axotomy. These results suggest that Shh plays a regulatory role in nerve injury.

Key words: Shh; neuronal death; axotomy; facial nerve; motor neuron; adenovirus

\section{Introduction}

The neuronal responses after peripheral nerve injuries have been intensively characterized and are certainly one of the best characterized models of neuronal regeneration. Facial nerve axotomy of rats, with its extensive abilities to regenerate in adults, provides us with a useful model in which to study the molecular mechanisms of nerve regeneration. It is well known that facial nerve axotomy in neonatal rats induces motor neuron death of the facial nucleus, whereas most of the neurons survive in adult rats (Graeber et al., 1998). The lack of regenerative properties of neonatal rat neurons is partly attributable to insufficient trophic supports from their target (Skene, 1989; Sendtner et al., 1992; Schnell et al., 1994; Yan et al., 1995; Fournier and McKerracher, 1997), but the molecular mechanisms of the axotomy-induced neuronal death in neonatal rats remain to be fully elucidated. To investigate the mechanisms that are responsible for promotion of motor neuron survival, we searched molecules whose mRNA expression is altered after nerve injury. We found that Sonic hedgehog (Shh) expression was significantly upregulated in the cell bodies of motor neurons after facial nerve axotomy.

Shh has been intensively characterized in the developmental

Received Sept. 9, 2003; revised July 12, 2004; accepted July 14, 2004.

This work was supported by grants from the Ministry of Health, Labor, and Welfare, Japan (C.A. and S.K.), from the Ministry of Education, Science, Sports, Culture, and Technology, Japan (C.A. and S.K.), and from the Sankyo Life Science Foundation (C.A.). We thank A.P. McMahon, N. Osumi, and M. Nakafuku for sharing experimental materials. We are grateful to T. M. Jessell and I. Kanazawa for discussion. The anti-Shh monoclonal antibody developed by T. M. Jessell was obtained from the Developmental Studies Hybridoma Bank under the auspices of the National Institute of Child Health and Human Development and maintained by the University of lowa, Department of Biological Sciences (lowa City, IA).

Correspondence should be addressed to Chihiro Akazawa, Department of Neurochemistry, National Institute of Neuroscience, National Center of Neurology and Psychiatry, Ogawahigashi 4-1-1, Kodaira, Tokyo 187-8502, Japan. E-mail: akazawa@ncnp.go.jp.

DOI:10.1523/JNEUROSCI.1784-04.2004

Copyright $\odot 2004$ Society for Neuroscience $\quad 0270-6474 / 04 / 247923-08 \$ 15.00 / 0$ stages of various organs, including motor neuron differentiation (Richardson et al., 1997; Pfaff and Kintner, 1998; Briscoe et al., 1999; Soula et al., 2001), limb development (Te Welscher et al., 2002), hair follicle formation, and odondogenesis (St-Jacques et al., 1998). In the developing neural tube, the secretion of Shh from the notochord and floor plate organizes the pattern of ventral neurogenesis along the entire length of the CNS. Shh also plays an important role in the phenotypic specification of ventral neurons. For example, Shh induces the differentiation of motor neurons in the spinal cord and dopaminergic neurons in the midbrain (Tanabe et al., 1995; Pfaff and Kintner, 1998; Briscoe et al., 1999). Although the expression of Shh persists in the adult brain beyond this induction period, little is known about its functional role in adults. A goal of this study is to characterize Shh expression in matured motor neurons after nerve injuries. We performed adenoviral gene transfer of chick Shh to overexpress Shh in the axotomized motor neurons of neonatal rats as a gainof-function approach. Finally, we analyzed the effect of pharmacological inhibition of Shh signaling in the axotomized motor neurons of adult rats as a loss-of-function approach.

\section{Materials and Methods}

Animals. Adult Wistar rats (200-250 gm) were housed in the animal facility of National Institute of Neuroscience, National Center of Neurology and Psychiatry. The first $24 \mathrm{hr}$ after birth is postnatal day 0 (P0). All animal experiments and care protocols were performed under the approval of the ethical committee on laboratory animals of the institute.

Recombinant adenovirus vectors and Shh antagonist application. The construction and characterization of the adenovirus (AdV) carrying the gene for chick Shh or $\beta$-galactosidase (lacZ) was described previously (Ohsaki et al., 2002). The AdV was concentrated by cesium chloride density gradient centrifuge. The concentrated AdV was dialyzed with PBS. Cyclopamine (Toronto Research Chemicals, North York, Ontario, 
Canada) or tomatidine (Sigma, St. Louis, MO) was dissolved at a concentration of 1.0 or 5.0 $\mu \mathrm{g} / \mathrm{ml}$ in $45 \%$ (w/v) 2-hydroxypropyl- $\beta$ cyclodextrin (HBC) (Sigma) in PBS (Berman et al., 2002; Lai et al., 2003).

Facial nerve transection. Under ether anesthesia, the facial nerve was transected at the stylomastoid foramen (Graeber et al., 1998). In all experiments, the unoperated contralateral sides serve as a control. For the AdV type V vector, cyclopamine or tomatidine application involved a $1.0 \mathrm{~mm}^{3}$ Gelfoam (Amersham Biosciences Japan, Tokyo, Japan) soaked with a $1.0 \times 10^{10}$ multiplicity of infection of AdV, $2 \mu \mathrm{l}$ of cyclopamine $(1.0$ or $5.0 \mu \mathrm{g} / \mathrm{ml})$, or $2 \mu \mathrm{l}$ of tomatidine implanted immediately at the nerve cut site. After the indicated intervals $(6,12$, and $24 \mathrm{hr}$ and 3, 5, 7, and $14 \mathrm{~d}$ ), rats were killed by cervical decapitation under deep anesthesia by ether. The brains were quickly removed without perfusion and frozen at $-70^{\circ} \mathrm{C}$ until use. Whole series of coronal sections $(14-\mu \mathrm{m}$-thick cryosections) were taken through the full extent of bilateral facial nuclei. The number of survived motor neurons was determined and counted by a blinded observer as described previously (Baumgartner and Shine, 1997). Five independent experiments were performed, and the total number of survived motor neurons was statistically analyzed (Student's $t$ test).

Subtraction cDNA library screening. Five series of pooled facial nuclei were subjected to total RNA isolation by the phenol-guanidine isothiocyanate method. Subtractions between axotomized nuclei and contralateral nuclei were performed by using the SMART subtraction kit (BD Biosciences Clontech, Palo Alto, CA). Three hundred clones were randomly sequenced to identify the insert cDNA.

In situ hybridization and immunohistochemistry. The coding region of rat Shh cDNA (accession number, NM_017221) was amplified by PCR using paired primers ( $5^{\prime}$-ATGCTGCTGCTGCTGGCCAGA- $3^{\prime}$ and $5^{\prime}$-TCAGCTGGACTTGACTGCCAT- $\left.3^{\prime}\right)$. The cDNA fragments for rat Patched1 (Ptc1) (accession number, AF079162) and rat Smoothened (Smo) (accession number, U84402) were amplified by the paired primers: $5^{\prime}$-ATGCTGAATAAAGCCGAAGT-3' and 5'-CACGAGGCTGACACAGGGGC-3' for Ptc1; and 5' -CTTCCGGGACTATGTGCTAT- ${ }^{\prime}$ ' and 5'-AGAAGTCCGAGTCTGCATCC-3' for Smo. The amplified fragment was subcloned into a pGEM-T easy vector (Promega, Madison, WI) and subsequently sequenced. Antisense and sense riboprobes were synthesized by transcription using either T7- or SP6-RNA polymerase (Roche Diagnostics, Manheim, Germany) in the presence of digoxigenin-UTP (Roche Diagnostics) for $30 \mathrm{~min}$ at $37^{\circ} \mathrm{C}$ according to the manufacturer's protocol. The digoxigenin-labeled RNA probe was column-purified and reconstituted in distilled water. The $16-\mu \mathrm{m}$-thick coronal sections containing bilateral facial nuclei were fixed in $4 \%$ paraformaldehyde in $0.1 \mathrm{M}$ PBS for $20 \mathrm{~min}$ and washed in PBS, and sections were hybridized overnight at $65^{\circ} \mathrm{C}$ in a mixture (50\% formamide, 10 mm PBS, 20 mu Tris $\mathrm{HCl}$, pH 7.4, 5 mм EDTA, 10\% dextransulfate, $1 \times$ Denhardt's reagent, $0.2 \%$ sodium laurylsarcosine, 500 $\mu \mathrm{g} / \mathrm{ml}$ tRNA, and $200 \mu \mathrm{g} / \mathrm{ml}$ sonicated sermon sperm DNA) containing labeled probe $(0.5 \mu \mathrm{g} / \mathrm{ml}$ in hybridization mixture $)$. After hybridization, sections were washed in $10 \mathrm{~mm}$ dithiothreitol in $5 \times \mathrm{SSC}$ at $55^{\circ} \mathrm{C}$. After washing, alkaline phosphatase-conjugated anti-digoxigenin antibody staining was performed following a chromogenic reaction containing nitroblue tetrazolium and 5-bromo-4-chloro-3-indolylphosphate. After capturing the images, sections were counterstained with Nissl, dehy-

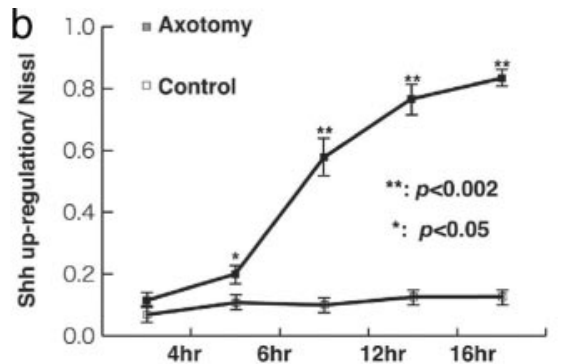

C
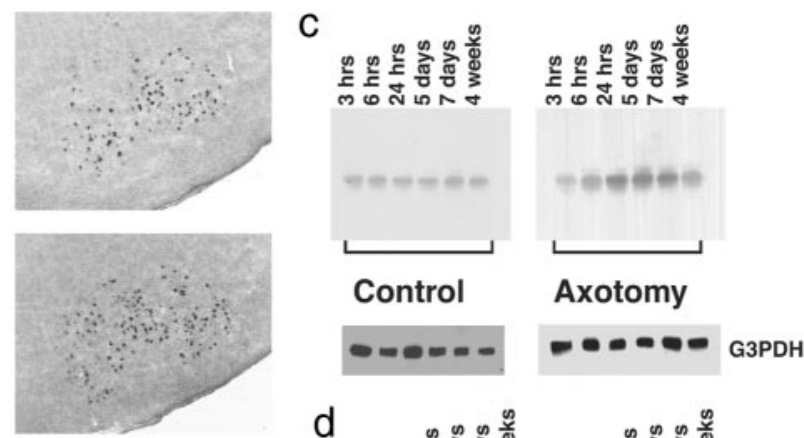

d
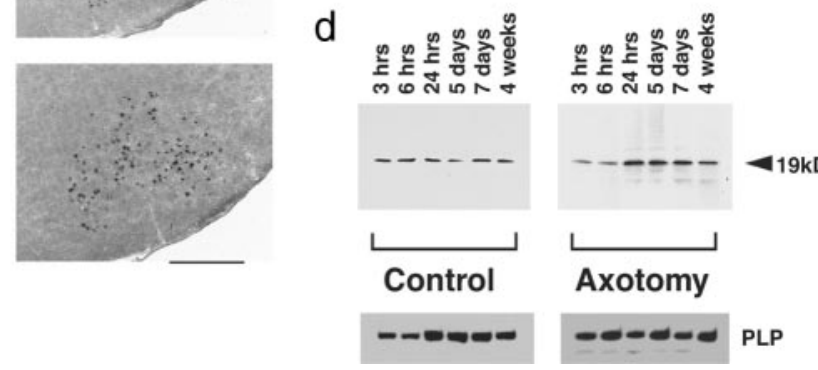

Figure 1. a, Upregulated expression of Shh after axotomy in adult rats: in situ hybridization of Shh antisense riboprobes in a coronal section at 3,6, and $24 \mathrm{hr}$ and $5 \mathrm{~d}$ after the axotomy. The relatively large size of cells corresponding to motor neurons in facial

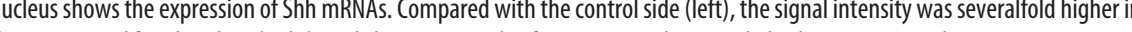
control blot using radiolabeled G3PDH for Northern blot and anti-PLP antibody for Western blot revealed that relatively equal amounts of RNA and protein were loaded in each lane.

drated in a graded series of ethanol, and coverslipped with DePeX (BDH Chemicals, Poole, UK).

Double fluorescent-labeling analyses were performed to identify the cellular expression of adenovirus-mediated Shh using mouse monoclonal anti-Shh antibody (5E1; 1:500 dilution; Developmental Studies Hybridoma Bank) in combination with polyclonal antibodies against p75NTR (neurotrophin receptor) (rabbit anti-human p75; 1:1000 dilution; Promega), GAP-43 (growth-associated protein-43) (N-19; goat anti-human GAP-43; 1:2000 dilution; Santa Cruz Biotechnology, Santa Cruz, CA), Iba1 (rabbit anti-Iba1; 1:1000 dilution) (Imai et al., 1996), and GFAP (rabbit anti-GFAP; 1:500 dilution; Dako, Glostrup, Denmark). Cryosections fixed with $4 \%$ paraformaldehyde, $0.5 \%$ Triton $\mathrm{X}-100$, and PBS were incubated with primary antibodies overnight at $4^{\circ} \mathrm{C}$ and washed and incubated with the secondary antibodies. Fluorescent images were captured by using a Leica confocal microscope (TSC-SP2; Leica Microsystems, Wetzler, Germany).

Northern and Western blotting. Rat facial motor nuclei (five pooled animals) were homogenized in $100 \mu$ l of lysis buffer (50 mM HEPES, pH 7.5, $150 \mathrm{~mm} \mathrm{NaCl}, 1.5 \mathrm{~mm} \mathrm{MgCl}_{2}, 5$ mм EGTA, 10\% glycerin, $1 \%$ Triton $\mathrm{X}-100,0.1 \mathrm{~mm} \mathrm{Na}_{3} \mathrm{VO}_{4}, 10 \mu \mathrm{g} / \mathrm{ml}$ aprotinine, $10 \mu \mathrm{g} / \mathrm{ml}$ leupeptine, and 1 mM phenylmethylsulfonyl fluoride). Lysates were then centrifuged at $12,000 \times g$ for $20 \mathrm{~min}$ at $4^{\circ} \mathrm{C}$. The protein concentration was quantified using a modification of the Bradford assay (Bio-Rad, Munich, Germany). Total cell lysate $(10 \mu \mathrm{g})$ was electrophoresed through $7.5 \%$ SDS 
polyacrylamide gels and electroblotted on nitrocellulose membranes (Schleicher \& Schnell, Dassel, Germany). The blots were incubated overnight at $4^{\circ} \mathrm{C}$ with rabbit anti-Shh $(1: 2000$; a generous gift from A. P. McMahon, Harvard University, Cambridge, MA) or anti-goat antimyelin proteolipid protein (PLP) (Santa Cruz Biotechnology) in $10 \mathrm{~mm}$ Tris $\mathrm{HCl}, \mathrm{pH} 8.0,150 \mathrm{~mm} \mathrm{NaCl}$, and $0.05 \%$ Tween 20 containing $1 \%$ BSA.

RNase protection assay. For detection of Smoothened and Patched mRNA, equal amounts of total RNA $(30 \mu \mathrm{g})$ were subjected to RNase protection assay as described previously (Funakoshi et al., 1993). Radiolabeled antisense riboprobes were generated in the presence of $\left[\gamma^{-}{ }^{32} \mathrm{P}\right]$ CTP using SP6- or T7-RNA polymerase. Glyceraldehyde 3-phosphate dehydrogenase (G3PDH) was used for subsequent standardization. After the RNase digestion, protected fragments were separated in urea-denatured $4 \%$ polyacrylamide gels and exposed to $\mathrm{x}$-ray films with intensifying screens at $-70^{\circ} \mathrm{C}$.

\section{Results}

\section{Identification of Shh as an upregulated molecule after facial} nerve axotomy

We sequenced 300 clones from the subtraction cDNA library between axotomized and contralateral facial nuclei at $24 \mathrm{hr}$ after axotomy. By searching the BLAST database, 182 clones were identical to transcripts from known genes, and 118 clones were unknown (data not shown). Some of the known genes, such as galectin-1 (Akazawa et al., 2004), GFR $\alpha$-1 (glial cell line-derived neurotrophic factor family receptor $\alpha 1$ ) (Tsujino et al., 1999), GLT-1 (glutamate transporter-1) (Lopez-Redondo et al., 2000), p75NTR (Gschwendtner et al., 2003), and GAP-43 (Doster et al., 1991), were already described as upregulated after axotomy of facial or hypoglossal nerves. We found four transcripts of Shh and one transcript of Smo as upregulated molecules.

Upregulation of Shh in the facial motor neurons of adult rats In situ hybridization was performed to characterize the cellular expression of Shh after facial nerve axotomy. The motor neurons of adult facial nucleus express Shh mRNA at a low level (Fig. 1a, Control). On the side of axotomy, facial motor neurons started to show Shh transcripts at $6 \mathrm{hr}$ after the operation. The expression of Shh reached its peak at $24 \mathrm{hr}$ and continued at high levels until 4 weeks after the operation. To quantify the population of Shh-upregulated motor neurons in the axotomized facial nucleus, the sections were counterstained by Nissl to identify motor neurons. The number of neurons that upregulated Shh transcripts and the number of Nisslpositive cells were counted in the same sections, and the ratio was shown (Fig. 1b). Almost $83 \pm 1.4 \%$ of Nissl-positive neurons upregulated Shh at $18 \mathrm{hr}$ after the axotomy, whereas in the control side, $<20 \%$ of Nissl-positive neurons express Shh. To semiquantify the Shh increase, we performed Northern blot analysis for the total RNA purified from pooled facial nuclei from five independent experiments (Fig. 1c). Transcripts of Shh were present at a low level at $3 \mathrm{hr}$ after axotomy. The initial increase was detected at $6 \mathrm{hr}$ and reached its peak at $\sim 24 \mathrm{hr}$, followed by a subsequent decline. We next tested the protein expression of Shh by Western blot analysis. The $19 \mathrm{kDa}$ single band was detected, and the expression increased from $24 \mathrm{hr}$ after axotomy and was sustained for up to 1 month (Fig. 1d). From these experiments, facial nerve axotomy induces the expression of Shh transcripts and proteins in motor neurons of adult rats.

\section{Upregulation of Smo after axotomy}

The Shh receptor consists of at least two components, Ptc1 for ligand binding and Smo for downstream signaling (Ho and Scott, 2002). We next tested whether axotomy of adult rats alters the expression of the Shh receptor. We performed RNase protection
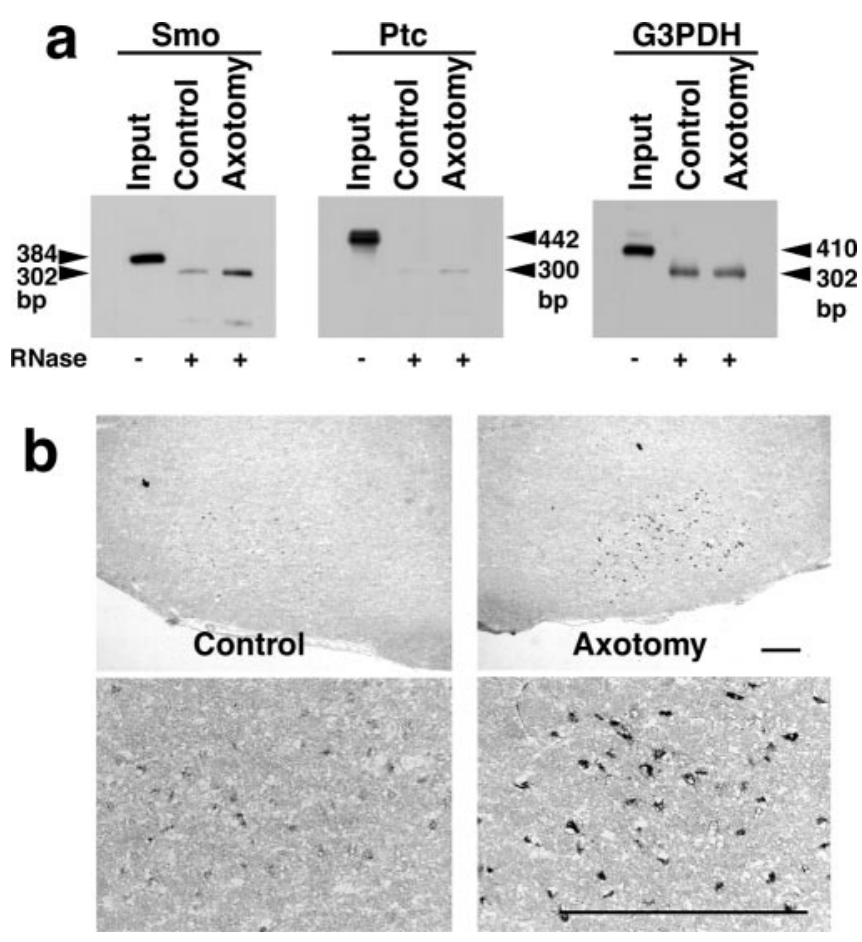

Figure 2. Expression of the Shh receptor Smo and Ptc in the facial nucleus of control and axotomized adult rats at $24 \mathrm{hr}$ after axotomy. $a$, The total RNA (30 $\mu \mathrm{g}$ ) purified from pooled facial nuclei was subjected to RNase protection analyses. For the expression of Smo, a 384 bp antisense riboprobe was hybridized, and a $302 \mathrm{bp}$ band was protected after RNase digestion. For the expression of Ptc1, a 442 bp antisense riboprobe yielded a 300 bp protected band after RNase digestion. Control experiments using a G3PDH antisense riboprobe showed that equal amounts of total RNA were used in these experiments. $b$, In situ hybridization histochemistry showing the cellular localization of Smo transcripts in facial nucleus. The axotomy of adult rat facial nerve induced upregulated expression of Smo mRNA in the cell bodies of motor neurons. Scale bar, $500 \mu \mathrm{m}$.

analysis to detect the transcripts of Smo, Ptc1, and G3PDH, respectively (Fig. 2a). Radiolabeled antisense riboprobes corresponding to the $384 \mathrm{bp}$ of Smo, $442 \mathrm{bp}$ of Ptcl, and $410 \mathrm{bp}$ of G3PDH yielded 302, 300, and 302 bp of protected band after RNase digestion, respectively. The expression of Smo mRNA was upregulated at $24 \mathrm{hr}$ after axotomy, whereas no change in Ptc1 and G3PDH expression was observed between axotomized and control facial nuclei. The intensity of protected bands in G3PDH showed that relatively equal amounts of RNA were used in the experiments. To further investigate the cellular expression of Smo, in situ hybridization histochemistry was performed (Fig. $2 b$ ). The Smo mRNA was detected in the facial motor neurons of the control side, albeit at a low level. Facial nerve axotomy of adult rats induced upregulated expression of Smo mRNA in the motor neurons at $24 \mathrm{hr}$ after axotomy. No upregulated expression of Ptcl mRNA was detected by in situ hybridization (data not shown).

\section{No upregulation of Shh and Smo in neonatal rats}

It is well characterized that neonatal facial nerve axotomy induces motor neuron cell death $\sim 5 \mathrm{~d}$ after axotomy. We next tested whether Shh expression was upregulated in neonates after axotomy. Although the basal level of Shh expression was detected in cell bodies of motor neurons at P2, that is, $24 \mathrm{hr}$ after axotomy (Fig. $3 a$, Control), the facial nerve axotomy did not induce Shh expression (Fig. 3a, Axotomy). To further investigate the time course and semiquantification of molecules after axotomy, Northern and Western blot analyses were performed by using 
total RNA and total protein lysates purified from facial nuclei collected from five independent experiments. No upregulation of Shh transcripts and polypeptides was detected after axotomy of neonatal rats (Fig. 3b,c). The Shh expression was not detected $5 \mathrm{~d}$ after axotomy in the axotomized facial nuclei. This is because of the axotomy-induced neuronal death in neonates. We next tested whether axotomy of neonatal rats alters the expression level of Smo by RNase protection analysis. The protected bands were clearly detected for both Smo and Ptc1, although there was no change of expression between control and axotomized facial nuclei (Fig. 3d). Neonatal rats lack the upregulation of both Shh and Smo after axotomy.

\section{Motor neuron survival promoted by Shh-adenovirus in neonatal rats}

To test the possibility that the upregulated expression of Shh may relate to the survival of axotomized motor neurons, we implanted a Gelfoam $\left(1.0 \mathrm{~mm}^{3}\right)$ soaked with a $1 \times 10^{10}$ multiplicity of infection of AdV vector containing chick Shh (AdV-Shh) (Ohsaki et al., 2002) or $\beta$-galactosidase (AdV-lacZ) at the proximal stump of facial nerve immediately after the bilateral axotomy. First, to test the efficacy of gene transfer by AdV, we compared the lac $Z$ staining after the operation of neonatal and adult rats. Operations were performed at $\mathrm{P} 1$ and adult (200-250 gm), and Gelfoams soaked with AdV-lacZ were implanted. We found that AdVmediated gene transfer is more effective in neonatal rats than in adult rats (see Fig. $6 a$ ). Thus, we used neonatal rats for the exogenous overexpression of Shh. We applied the AdV-Shh to the right side of the axotomized nerve stump and the AdVlacZ to the left side. Pups were treated for $4 \mathrm{~d}$ and then killed for sectioning. The sections were double-stained with anti-Shh rabbit polyclonal antibody and anti-lacZ monoclonal antibody and visualized with Alexa-Fluor 488- and Alexa-Fluor 594conjugated secondary antibodies, respectively. After capturing the confocal images, the sections were stained with Nissl to obtain neuronal nuclear staining. There is a significant increase of Nissl stainingpositive cells in the AdV-Shh-infected side (Fig. 4b) compared with the AdVlacZ-infected side (Fig. 4a). Antibody staining showed the overexpressed Shh was only detected in the AdV-Shh-infected side (Fig. 4d). When we compared the Nissl staining with anti-Shh staining, Shhtransferred motor neurons formed a cluster-like staining. Western blotting analysis confirmed the overexpression of chick Shh only in the AdV-Shh-infected side (data not shown).

a

b
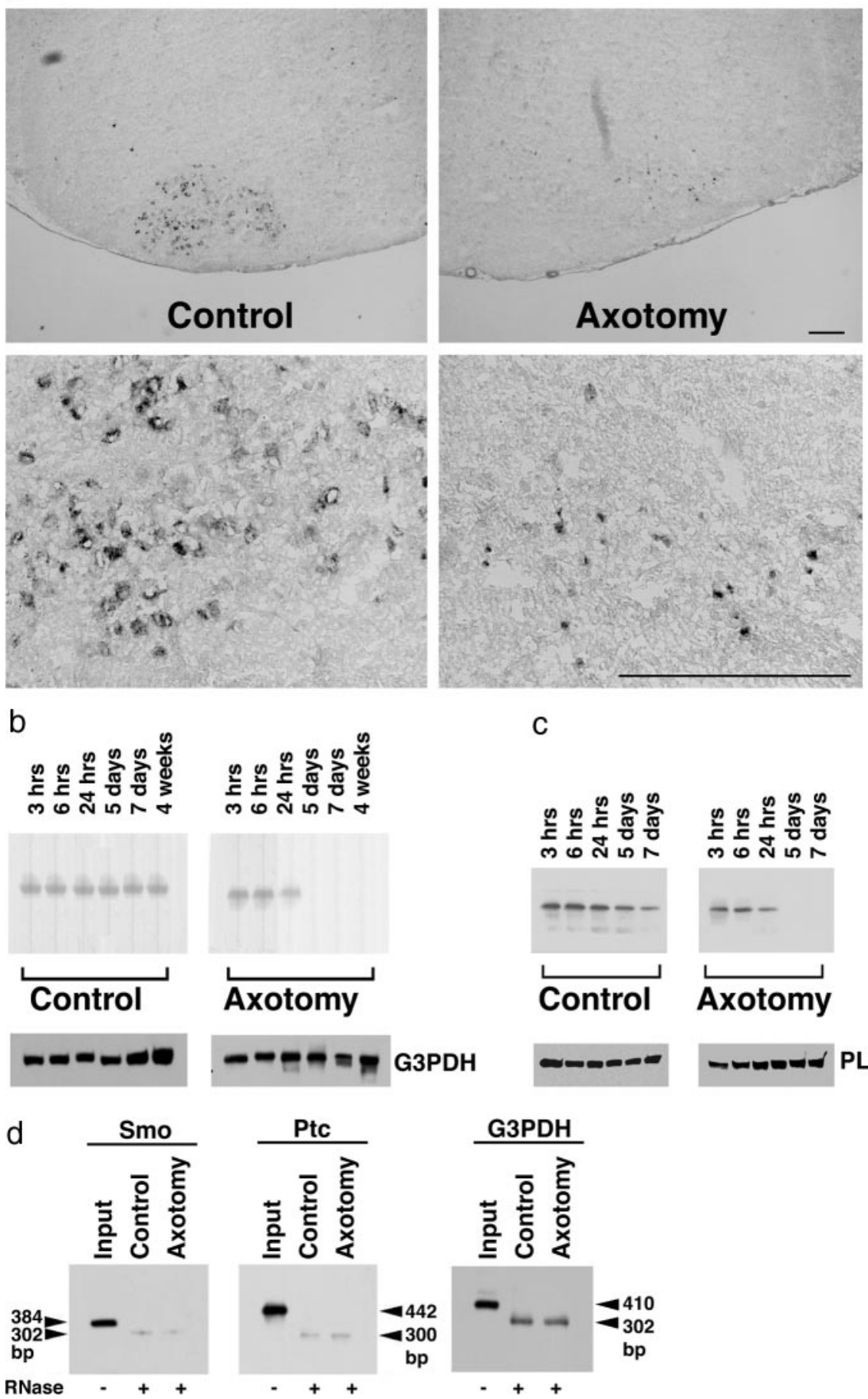

Figure 3. a, In situ hybridization histochemistry of Shh in neonatal rats at $24 \mathrm{hr}$ after axotomy. The control side of facial motor neurons expresses Shh mRNA at a low level, whereas axotomy of facial nerves rather suppresses the Shh expression. Scale bar, 100 $\mu \mathrm{m} . b, c$, Quantitative analyses of Shh expression after axotomy by Northern blot $(b)$ and Western blot $(c)$ analyses. Each lane contains $30 \mu \mathrm{g}$ of total RNA $(b)$ and $10 \mu \mathrm{g}$ of total protein lysates $(c)$ purified from pooled facial nuclei corresponding to representative time course. No expression of Shh mRNA and protein was detected in the facial nuclei after $5 \mathrm{~d}$ in axotomized neonatal rats because the axotomy of neonatal rats induces motor neuron death. Control blots were performed using radiolabeled G3PDH or anti-PLP antibody. $d$, The RNase protection analysis revealed that axotomy of neonatal rat facial nerves did not induce the expression of Smo and Ptc1 mRNA.

To identify the cell types infected with AdV-Shh, fluorescent double staining was performed in neonatal rats. The immunoreactivities of anti-Shh monoclonal antibody were visualized with the secondary antibody conjugated with Alexa-Fluor 488 (Fig. 5, green). Rabbit polyclonal antibodies against p75NTR or GAP-43 
AdV-lacZ
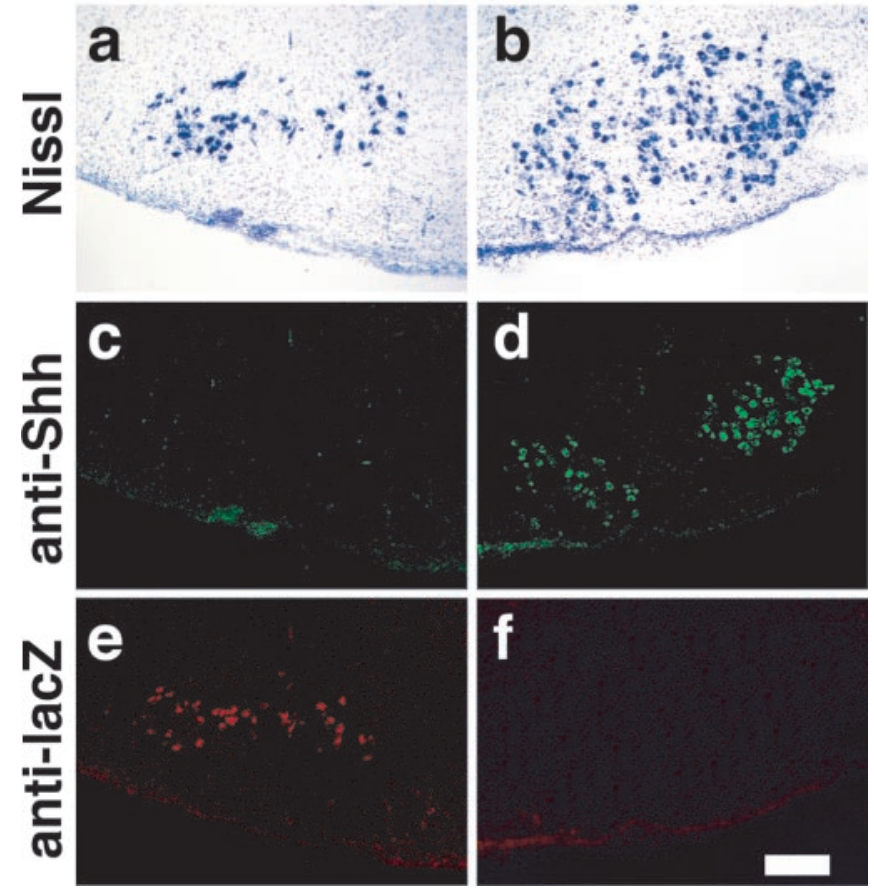

Figure 4. We tested the effect of Shh overexpression in neonatal rats by the implantation of Gelfoams containing AdV-lacZ in the left operation side and Gelfoams containing AdV-Shh in the right operation side. At $3 \mathrm{~d}$ after the operation, the cryosections were stained with rabbit polyclonal anti-Shh $(c, d)$ and mouse monoclonal anti-lacZ $(e, f)$ antibodies visualized with Alexa-Fluor 488-conjugated (green) and Alexa-Fluor 594-conjugated (red) secondary antibodies. After capturing the confocal images, sections were stained with Nissl to visualize the neuronal nuclear staining $(a, b)$. Five independent experiments were performed, and a representative result is shown. Scale bar, $500 \mu \mathrm{m}$.

were used to identify the motor neurons of facial nucleus. For non-neuronal marker stainings, rabbit polyclonal antibodies against Ibal or GFAP were used. The immunoreactivities of neuronal or non-neuronal markers were visualized by the secondary antibody conjugated with Alexa-Fluor 594 (Fig. 5, red). The expression of Shh (Fig. 5, arrows), which was only detected in the lesioned facial nuclei, overlapped well with the immunoreactivities of p75NTR or GAP-43. Meanwhile, non-neuronal markers, such as Iba1 that localizes in the cell bodies of microglia-macrophage (Fig. 5, m) and GFAP that localizes in astrocytes (Fig. 5, a), were barely detected in the Shh-positive cells.

\section{Time course of survival-promoting effect of Shh overexpression in neonatal rats}

Given the potent in vitro action of AdV-Shh on axotomized motor neurons of neonates, we next looked for the time course of this effect (Fig. 6b). At $4 \mathrm{~d}$ after the operation, lesioned neonates that were treated with AdV-lacZ retained only $0.37 \pm 0.07 \times 10^{4}$ cells of their facial motor neurons. In contrast, the lesioned facial nuclei that received AdV-Shh showed $0.88 \pm 0.07 \times 10^{4}$ cells stained with Nissl, undistinguishable from the nonlesioned side. The difference in neuronal survivals between the AdV-Shh and AdV-lacZ was statistically significant $(n=5 ; t=21.9 ; p<0.001)$. However, this effect was only retained for 1 week. At 2 weeks after the operation, the motor neurons that received AdV-Shh finally shrank, and the cellular organization of the facial nucleus was no longer observed. Thus, AdV-Shh can prevent death of axotomized neonatal motor neurons, although this is transient and insufficient to attenuate the full survival. To exclude the toxicity of AdV treatment, we compared the number of the Nissl-positive neurons between the AdV-lacZ-infected facial nuclei and PBSapplied facial nuclei. There is no significant difference in the number of survived cells between AdV-infected neurons and PBS-applied neurons (Fig. 6c). This means that there is no toxic effect of $\mathrm{AdV}$, and the survival of our current result may be solely attributable to the overexpression of Shh.

\section{Inhibition of Shh signaling in adult rat axotomy}

To examine whether the inhibition of Shh signaling would reduce the regeneration of axotomized motor neurons in adult rats, the Gelfoam was soaked with cyclopamine, a specific inhibitor of Shh signaling shown to act by direct binding to the heptahelical bundle of Smo (Chen et al., 2002b), tomatidine (Berman et al., 2002), an inactive analog of cyclopamine, or with the vehicle $\mathrm{HBC}$ and implanted at the axotomized region. $\mathrm{HBC}$ has been extensively used to increase the solubility of hydrophobic compounds for delivery to the brain with no observed side effects (Lai et al., 2003). At $7 \mathrm{~d}$ after the implantation of cyclopamine, tomatidine, or vehicle alone, sections covering bilateral facial nuclei were prepared, and the total number of Nissl-positive motor neurons was counted. Five independent rats were operated on and subjected to the statistical analyses (Student's $t$ test). The implanted cyclopamine reduced the number of Nissl-positive neurons by $\sim 60 \%$ in a dose-dependent manner compared with the control vehicle side (Fig. 7). Meanwhile, the implanted tomatidine did not influence the number of Nissl-positive neurons.

\section{Discussion}

Nerve injuries induce a variety of molecular responses such as neurotrophic factors, cytokines, growth factors, and extracellular molecules that may be involved to some extent in the regeneration of injured neurons (Skene, 1989; Doster et al., 1991; Sendtner et al., 1992; Schnell et al., 1994; Yan et al., 1995; Fournier and McKerracher, 1997). In the course of searching the molecules whose expression is altered in adult rat motor neurons of facial nucleus after axotomy, we found that Shh expression was upregulated from $24 \mathrm{hr}$ after axotomy and declined at 4 weeks. The physiological roles of Shh have been intensively characterized in vertebrate development. It specifies the identity of different cell types in the ventral neural tube in early development (Pfaff and Kintner, 1998; Briscoe et al., 1999; Oppenheim et al., 1999). Although Shh is strong in inducing motor neurons from progenitor cells, there have been few reports characterizing its role in matured neurons (Miao et al., 1997; Traiffort et al., 1998, 1999; Ho and Scott, 2002). This is the first evidence that nerve axotomy induces upregulation of both Shh and Smo. This coordinated expression pattern, of both the ligand and receptor, in adult motor neurons strongly suggests that Shh may act on motor neurons in an autocrine manner. Another possibility is that Shh may act on their surrounding cells such as astrocytes, microglial cells, and Schwann cells to release molecules mediating motor neuron survival. Although the precise molecular circuit still remains unclear, our findings imply the novel function of Shh in matured motor neurons altering its expression level after nerve injury. Recently, new roles of Shh have been intensively characterized. In the adult hippocampus, Shh has been shown as a regulator of stem cell proliferation (Lai et al., 2003). It was also reported that Shh can directly attract spinal cord axons and commissural axons as a chemoattractant (Trousse et al., 2001; Charron et al., 2003). It is interesting that, in addition to its earlier role in development, Shh may function later in a novel role in the adult brain. Addi- 
tional studies will confirm how widely this key molecule is used not just in the embryo but also in the adult nervous system.

It has not been fully elucidated why axotomy of neonatal rats results in the cell death of motor neurons, whereas axotomy of adult rats results in successful regeneration (Graeber et al., 1998). Although a number of molecules involved in the repair process have been identified and characterized, the precise timing of these cascades may be critical to understand the process of nerve regeneration. We found a quite contrasting result that only adult rat axotomy induces the upregulation of Shh and Smo expression, whereas neonatal rat axotomy does not. Thus, we tested the gain of function of Shh on axotomized neonatal rats. We observed that AdVmediated gene transfer of Shh after axotomy of neonatal rats transiently endows the axotomized motor neurons with the ability to survive. The modified AdV used in our studies infects cells through a receptor-mediated mechanism. AdV vectors can infect cells in vivo to express a high level of the transgene within hours after infection (Moriyoshi et al., 1996; Verma and Somia, 1997). In somatic tissues, the expression sometimes lasts for 5-10 d after infection, attributable in part to viralinduced immune responses of the recipients. In fact, there are also reports describing a relatively limited period of gene transfer via AdV vectors (Baumgartner and Shine, 1998; Hottinger et al., 2000). In our experiments, it is possible that the survival-promoting effect of Shh is influenced by adenovirus toxicity, limiting the number and the duration of survived neurons. The modification of viral vector and transfer methods is necessary to improve the efficacy of regeneration. Alternatively, the development of pharmacological agonist-antagonist Shh signaling will be also beneficial if oral treatment is effective, as described recently (Chen et al., 2002a; Machold et al., 2003).

We assessed the cellular expression of AdV-Shh in the lesioned facial nucleus. Immunoreactivities of Shh were strongly observed in the cell bodies of facial motor neurons but were not detected in the cell bodies of astrocytes or microglia. Based on our current observations, the selective upregulation of Shh and Smo in axotomized motor neurons may serve in multiple pathways. The Shh may function as a survival factor per se in an autocrine manner. The motor neurons in response to the Shh may influence surrounding cells through unidentified molecules. Alternatively, the secreted Shh may directly affect surrounding cells, although, at least in our experimental conditions, the expression of Ptcl and Smo was under the detection level in glial cells. In this paper, we described the immunoreactivities of Ibal that resides in microglia, and microglia-derived macrophages were detected in the cells adjacent to Shh-positive motor neurons. Phagocytic mi-
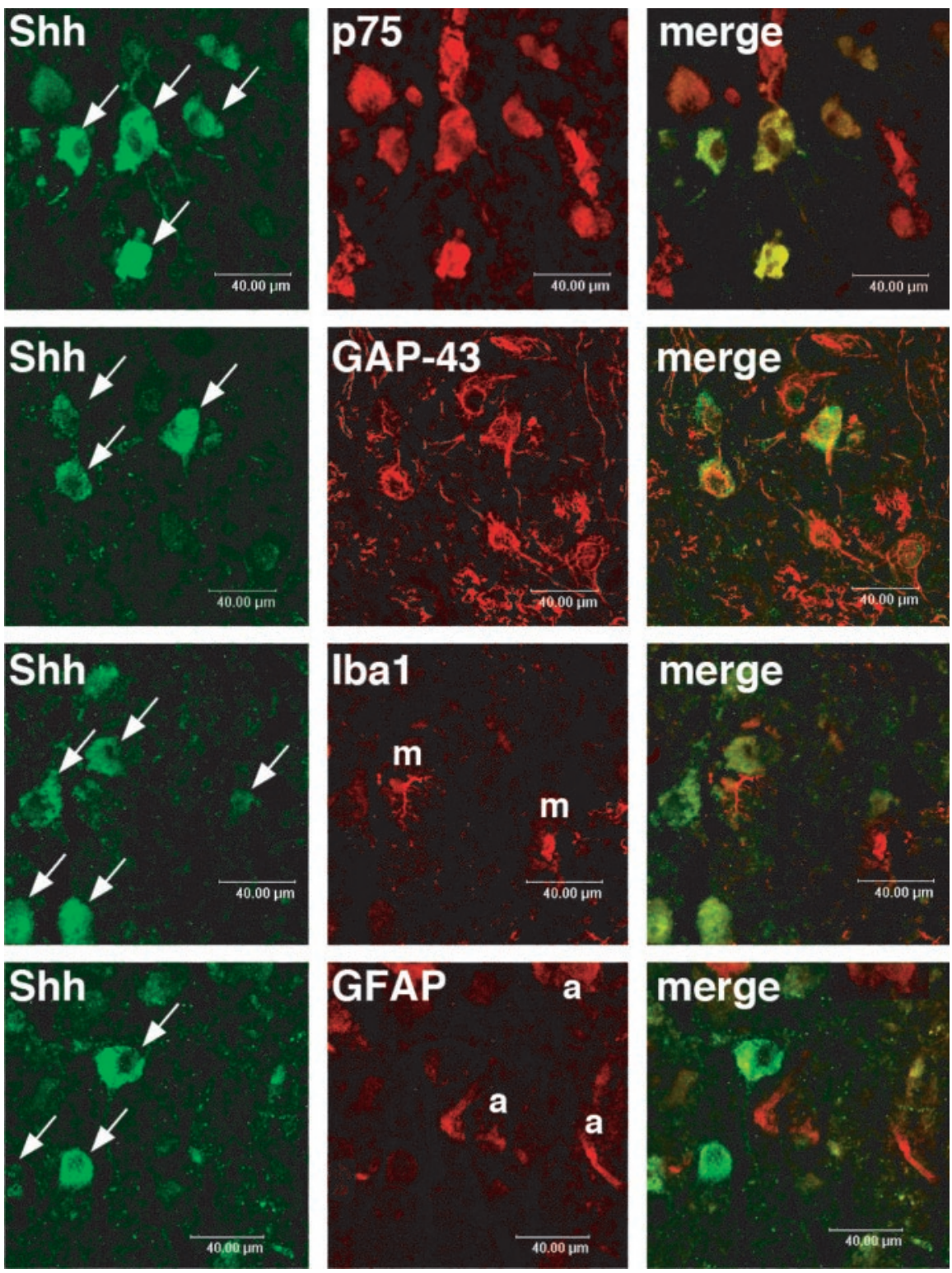

Figure 5. Cellular localization of adenovirus-mediated Shh expression in the lesioned facial nuclei of neonatal rats. The immunoreactivities of the anti-Shh monoclonal antibody were visualized with Alexa-Fluor 488 (green, left). The neuronal (p75 and Fluor 594 (red, middle). Shh immunoreactivities (arrows) were observed in the cell bodies of p75-positive or GAP-43-positive neurons but not detected in the cell bodies of Iba1-positive (m) or GFAP-positive (a) cells. Scale bar, $40 \mu \mathrm{m}$.

croglia surround the injured neurons to remove the lethally damaged neurons to preserve functional and structural architects of the lesioned nervous system (Graeber et al., 1998). Additional studies on Shh signaling will clarify how precisely the cellular network is preserved in nerve regeneration.

Although exogenous Shh promotes the transient survival of axotomized motor neurons of neonatal rats, this does not answer the question of whether the endogenous Shh is involved in the regeneration of axotomized neurons. We used the steroidal alkaloid cyclopamine, which is known to inhibit the Shh signaling through the specific binding of cyclopamine and Smo, altering the signal transduction of Smo (Chen et al., 2002b). In the axotomized adult rats, the application of cyclopamine adjacent to the nerve cut site significantly reduced the number of Nissl-positive motor neurons in a dose-dependent manner, whereas its inactive analog tomatidine had no effect. Taken together with our present 

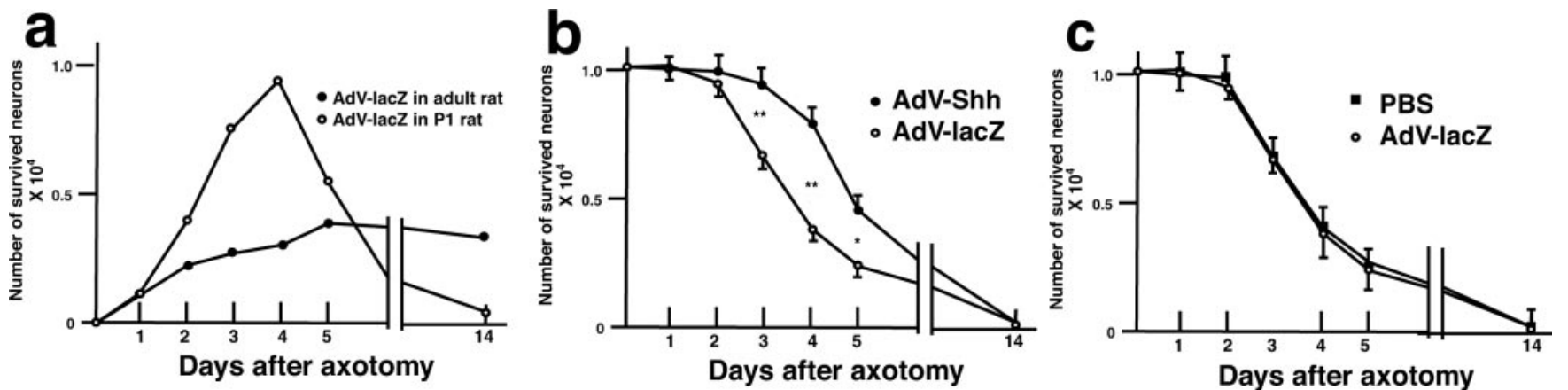

Figure 6. a, Efficacy of adenovirus-mediated overexpression of lacZ after axotomy in P1 and adult rats in the lesioned motor neurons. The pups were treated for $4 \mathrm{~d}$ after axotomy after the implantation of gelfoams containing AdV-lacZ. The number of lacZ-positive neurons was counted. In the neonatal rats, more lacZ-positive neurons were observed than in the adult rats by the adenovirus gene transfer. The number of Nissl-positive survived neurons was counted from the sections covering bilateral facial nuclei. Results of three independent experiments were subjected to statistical analysis (Student's $t$ test, ${ }^{*} p<0.01 ;{ }^{* *} p<0.001$ ). Shh-adenovirus significantly potentiates the survival of axotomized motor neurons from 3 to $5 \mathrm{~d}$ after axotomy and adenovirus application ( $a$ ). An application of adenovirus after axotomy did not influence the number of survived neurons compared with PBS application (b).

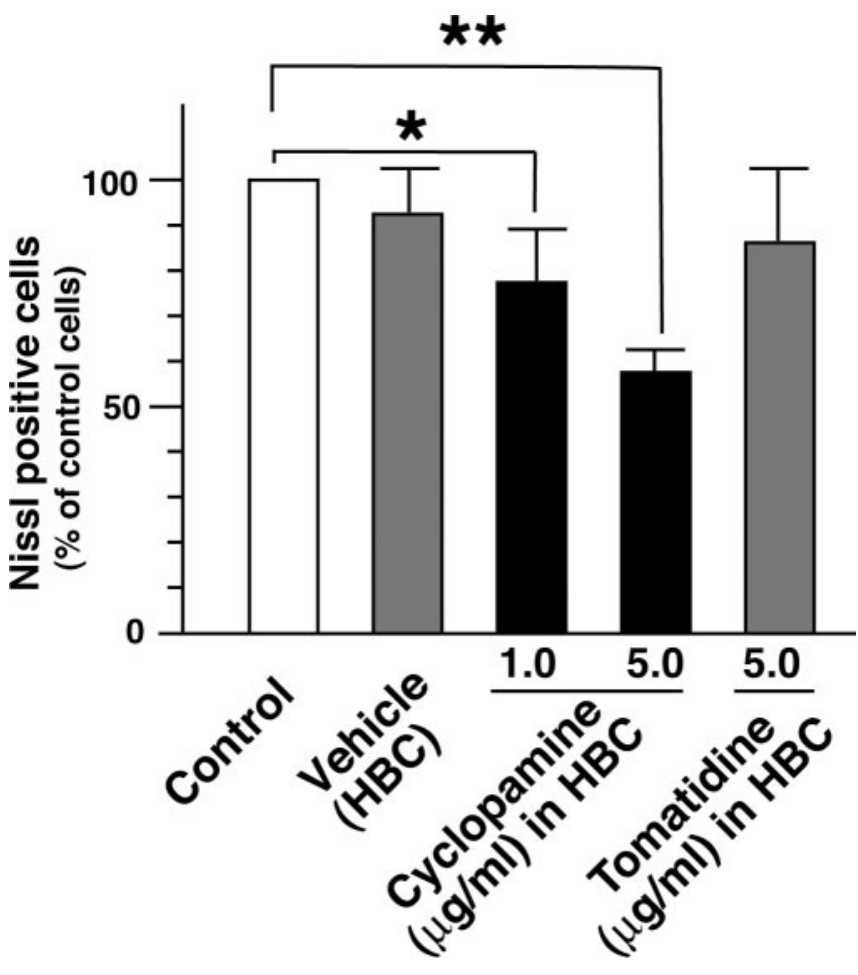

Figure 7. Inhibition of Shh signaling in axotomized adult rats. The cyclopamine application resulted in the loss of motor neurons in vivo. Bilateral facial nerves were axotomized and a Gelfoam soaked with cyclopamine $(1.0$ or $5.0 \mu \mathrm{g} / \mathrm{ml})$, with tomatidine $(5.0 \mu \mathrm{g} / \mathrm{ml})$, or with vehicle ( $45 \% \mathrm{w} / \mathrm{v} \mathrm{HBC}$ ) was implanted in each side. The total number of Nissl-positive cells was counted and compared between the implanted side and the control side. Five independent animals were operated on and statistically analyzed by Student's $t$ test $\left({ }^{*} p<0.05\right.$; ${ }^{* *} p<$ $0.01)$.

result, it is strongly suggested that endogenous Shh plays an important role in the adult brain, and this represents one of the few demonstrations of Shh function in the adult brain.

Our findings suggest that in addition to its earlier role in directing cellular fates in development, Shh functions as a regulatory role after nerve injury. This adds to a rapidly growing list of factors that have been identified as key molecules in nerve regeneration. Although considerable progress has been made in recent years in defining the genetic and molecular control of nerve regeneration, characterization in detail of molecular cascades has lagged. Our results in vivo have a therapeutic implication of Shh for regeneration of neuronal tissues after injuries. Based on our in vivo studies, besides its well characterized effects during development, we propose the de novo function of Shh in the regeneration of injured motor neurons.

\section{References}

Akazawa C, Nakamura Y, Sango K, Horie H, Kohsaka S (2004) Distribution of the galectin-1 mRNA in the rat nervous system: its transient upregulation in rat facial motor neurons after facial nerve axotomy. Neuroscience 125:171-178.

Baumgartner BJ, Shine HD (1997) Targeted transduction of CNS neurons with adenoviral vectors carrying neurotrophic factor genes confers neuroprotection that exceeds the transduced population. J Neurosci 17:6504-6511.

Baumgartner BJ, Shine HD (1998) Permanent rescue of lesioned neonatal motoneurons and enhanced axonal regeneration by adenovirusmediated expression of glial cell-line-derived neurotrophic factor. J Neurosci Res 54:766-777.

Berman DM, Karhadkar SS, Hallahan AR, Pritchard JI, Eberhart CG, Watkins DN, Chen JK, Cooper MK, Taipale J, Olson JM, Beachy PA (2002) Medulloblastoma growth inhibition by hedgehog pathway blockade. Science 297:1559-1561.

Briscoe J, Sussel L, Serup P, Hartigan-O’Connor D, Jessell TM, Rubenstein JL, Ericson J (1999) Homeobox gene Nkx2.2 and specification of neuronal identity by graded Sonic hedgehog signaling. Nature 398:622-627.

Charron F, Stein E, Jeong J, McMahon AP, Tessier-Lavigne M (2003) The morphogen Sonic hedgehog is an axonal chemoattractant that collaborates with netrin-1 in midline axon guidance. Cell 113:11-23.

Chen JK, Taipale J, Young KE, Maiti T, Beachy PA (2002a) Small molecule modulation of Smoothened activity. Proc Natl Acad Sci USA 99:14071-14076.

Chen JK, Taipale J, Cooper MK, Beachy PA (2002b) Inhibition of Hedgehog signaling by direct binding of cyclopamine to Smoothened. Genes Dev 16:2743-2748.

Doster SK, Lozano AM, Aguayo AJ, Willard MB (1991) Expression of the growth-associated protein GAP-43 in adult rat retinal ganglion cells following axon injury. Neuron 6:635-647.

Fournier AE, McKerracher L (1997) Expression of specific tubulin isotypes increases during regeneration of injured CNS neurons, but not after the application of brain-derived neurotrophic factor (BDNF). J Neurosci 17:4623-4632.

Funakoshi H, Frisen J, Barbany G, Timmusk T, Zachrisson O, Verge VM, Persson H (1993) Differential expression of mRNAs for neurotrophins and their receptors after axotomy of the sciatic nerve. J Cell Biol 123:455-465.

Graeber MB, Lopez-Redondo F, Ikoma E, Ishikawa M, Imai Y, Nakajima K, Kreutzberg GW, Kohsaka S (1998) The microglia/macrophage response in the neonatal rat facial nucleus following axotomy. Brain Res 813:241-253.

Gschwendtner A, Liu Z, Hucho T, Bohatschek M, Kalla R, Dechant G, Raivich G (2003) Regulation, cellular localization, and function of the p75 neu- 
rotrophin receptor (p75NTR) during the regeneration of facial motoneurons. Mol Cell Neurosci 24:307-322.

Ho KS, Scott MP (2002) Sonic hedgehog in the nervous system: functions, modifications and mechanisms. Curr Opin Neurobiol 12:57-63.

Hottinger AF, Azzouz M, Deglon N, Aebischer P, Zurn AD (2000) Complete and long-term rescue of lesioned adult motoneurons by lentiviralmediated expression of glial cell line-derived neurotrophic factor in the facial nucleus. J Neurosci 20:5587-5593.

Imai Y, Ibata I, Ito D, Ohsawa K, Kohsaka S (1996) A novel gene ibal in the major histocompatibility complex class III region encoding an EF hand protein expressed in a monocytic lineage. Biochem Biophys Res Commun 224:855-862.

Lai K, Kaspar BK, Gage FH, Schaffer DV (2003) Sonic hedgehog regulates adult neural progenitor proliferation in vitro and in vivo. Nat Neurosci 6:21-27.

Lopez-Redondo F, Nakajima K, Honda S, Kohsaka S (2000) Glutamate transporter GLT-1 is highly expressed in activated microglia following facial nerve axotomy. Brain Res Mol Brain Res 76:429-435.

Machold R, Hayashi S, Rutlin M, Muzumdar MD, Nery S, Corbin JG, GritliLinde A, Dellovade T, Porter JA, Rubin LL, Dudek H, McMahon AP, Fishell G (2003) Sonic hedgehog is required for progenitor cell maintenance in telencephalic stem cell niches. Neuron 39:937-950.

Miao N, Wang M, Ott JA, D’Alessandro JS, Woolf TM, Bumcrot DA, Mahanthappa NK, Pang K (1997) Sonic hedgehog promotes the survival of specific CNS neuron populations and protects these cells from toxic insult in vitro. J Neurosci 17:5891-5899.

Moriyoshi K, Richards LJ, Akazawa C, O’Leary DD, Nakanishi S (1996) Labeling neural cells using adenoviral gene transfer of membrane-targeted GFP. Neuron 16:255-260.

Ohsaki K, Osumi N, Nakamura S (2002) Altered whisker patterns induced by ectopic expression of Shh are topographically represented by barrels. Brain Res Dev Brain Res 137:159-170.

Oppenheim RW, Homma S, Marti E, Prevette D, Wang S, Yaginuma H, McMahon AP (1999) Modulation of early but not later stages of programmed cell death in embryonic avian spinal cord by sonic hedgehog. Mol Cell Neurosci 13:348-361.

Pfaff S, Kintner C (1998) Neuronal diversification: development of motor neuron subtypes. Curr Opin Neurobiol 8:27-36.

Richardson WD, Pringle NP, Yu WP, Hall AC (1997) Origins of spinal cord oligodendrocytes: possible developmental and evolutionary relationships with motor neurons. Dev Neurosci 19:58-68.

Schnell L, Schneider R, Kolbeck R, Barde YA, Schwab ME (1994) Neurotrophin-3 enhances sprouting of corticospinal tract during development and after adult spinal cord lesion. Nature 367:170-173.

Sendtner M, Holtmann B, Kolbeck R, Thoenen H, Barde YA (1992) Brainderived neurotrophic factor prevents the death of motoneurons in newborn rats after nerve section. Nature 360:757-759.

Skene JH (1989) Axonal growth-associated proteins. Annu Rev Neurosci 12:127-156.

Soula C, Danesin C, Kan P, Grob M, Poncet C, Cochard P (2001) Distinct sites of origin of oligodendrocytes and somatic motoneurons in the chick spinal cord: oligodendrocytes arise from $\mathrm{Nkx} 2.2$-expressing progenitors by a Shh-dependent mechanism. Development 128:1369-1379.

St-Jacques B, Dassule HR, Karavanova I, Botchkarev VA, Li J, Danielian PS, McMahon JA, Lewis PM, Paus R, McMahon AP (1998) Sonic hedgehog signaling is essential for hair development. Curr Biol 8:1058-1068.

Tanabe Y, Roelink H, Jessell TM (1995) Induction of motor neurons by Sonic hedgehog is independent of floor plate differentiation. Curr Biol 5:651-658.

Te Welscher P, Zuniga A, Kuijper S, Drenth T, Goedemans HJ, Meijlink F, Zeller R (2002) Progression of vertebrate limb development through SHH-mediated counteraction of GLI3. Science 298:827-830.

Traiffort E, Charytoniuk DA, Faure H, Ruat M (1998) Regional distribution of Sonic Hedgehog, patched, and smoothened mRNA in the adult rat brain. J Neurochem 70:1327-1330

Traiffort E, Charytoniuk D, Watroba L, Faure H, Sales N, Ruat M (1999) Discrete localizations of hedgehog signaling components in the developing and adult rat nervous system. Eur J Neurosci 11:3199-3214.

Trousse F, Marti E, Gruss P, Torres M, Bovolenta P (2001) Control of retinal ganglion cell axon growth: a new role for Sonic hedgehog. Development 128:3927-3936.

Tsujino H, Mansur K, Kiryo-Seo S, Namikawa K, Kitahara T, Tanabe K, Ochi T, Kiyama H (1999) Discordant expression of c-Ret and glial cell linederived neurotrophic factor receptor alpha-1 mRNAs in response to motor nerve injury in neonate rats. Brain Res Mol Brain Res 70:298-303.

Verma IM, Somia N (1997) Gene therapy-promises, problems and prospects. Nature 389:239-242.

Yan Q, Matheson C, Lopez OT (1995) In vivo neurotrophic effects of GDNF on neonatal and adult facial motor neurons. Nature 373:341-344. 